\title{
The Effects of Self-Regulatory Strength, Content, and Strategies on Close Relationships
}

\author{
Laura B. Luchies, ${ }^{1}$ Eli J. Finkel, ${ }^{1}$ and \\ Gróinne M. Fitzsimons ${ }^{2}$ \\ ${ }^{1}$ Northwestern University \\ ${ }^{2}$ Duke University
}

\begin{abstract}
This article reviews the growing literature on the effects of self-regulatory strength (how much self-regulatory ability people have), self-regulatory content (the goals toward which people self-regulate), and self-regulatory strategies (the manner in which people self-regulate) on close relationships. The extant literature indicates that close relationships benefit when relationship partners (a) have greater versus less selfregulatory strength, (b) prioritize relationship-promotion goals versus self-protection goals, (c) facilitate versus obstruct each other's personal goal pursuits, (d) enact positive relationship behaviors using approach versus avoidance strategies, and (e) pursue shared goals using complementary versus similar regulatory focus strategies. Future research could fruitfully (a) delve deeper into the influences of self-regulatory content and strategies on relationships and (b) integrate multiple lines of research examining the effects of self-regulation on relationships.
\end{abstract}

What are the consequences of self-regulation? A vast body of research within clinical, organizational, personality, and social psychology has shown that good self-regulators - those who can direct their thoughts, feelings, and behaviors to facilitate achievement of

The preparation of this commentary was supported in part by the National Science Foundation (Grant No. 719780). Any opinions, findings, and conclusions or recommendations expressed in this material are those of the authors and do not necessarily reflect the views of the National Science Foundation.

Correspondence concerning this article should be addressed to Laura B. Luchies, Redeemer University College, 777 Garner Road East, Ancaster, ON L9K 1J4, Canada. Email: 1luchies@redeemer.ca.

Note: Corrections added on 6 January 2012 after first publication online on 19 October 2011: The page number for this article should be Page 1251-1279 (not 949-977), and have been corrected in the online version of this article.

Journal of Personality 79:6, December 2011

(C) 2010 The Authors

Journal of Personality (C) 2011, Wiley Periodicals, Inc.

DOI: $10.1111 / \mathrm{j} .1467-6494.2010 .00701 . x$ 
their goals - enjoy a multitude of personal benefits. Successful selfregulators tend to have more successful careers, better physical health, and greater life satisfaction and personal well-being than less successful self-regulators (e.g., Bandura, 1982; Baumeister, Heatherton, \& Tice, 1994; Emmons, 1986; Locke \& Latham, 2002; Mischel, Shoda, \& Rodriguez, 1989).

Until recently, research examining the consequences of selfregulation has focused on these intrapersonal consequences, leaving potential interpersonal consequences of self-regulation largely unexamined. That has changed, as a burgeoning body of research over the past decade has shown that good self-regulators and their relationship partners enjoy many interpersonal benefits as well. In fact, selfregulation is so important to social functioning that researchers have posited that it evolved primarily to help humans maintain important relationships with one another and preserve social order (Baumeister, 2005; Heatherton \& Vohs, 1998). In the present article, we review this work and describe the effects of self-regulation - which refers to the processes by which the self alters its own thoughts, feelings, and behaviors in a goal-directed manner (see Baumeister, Schmeichel, \& Vohs, 2007; Rawn \& Vohs, 2006) - on close relationships. We have included studies that both (a) measure or manipulate a self-regulatory process and (b) report the association or effect of this self-regulatory process with or on close relationships. We divide our discussion into three sections. First, we discuss the relational consequences of self-regulatory strength, or the amount of self-regulatory ability individuals have. Second, we discuss the relational consequences of self-regulatory content, or the goals toward which individuals self-regulate. Third, we discuss the relational consequences of selfregulatory strategies, or the manner in which individuals self-regulate.

\section{Self-Regulatory Strength}

One aspect of self-regulation that affects close relationships is the strength of an individual's self-regulatory ability. By self-regulatory strength, we mean the overall amount of self-regulatory ability available to the individual seeking to pursue a given goal. In this section, we review how chronic individual differences and temporary fluctuations in individuals' self-regulatory strength affect the quality of their close relationships. We discuss findings suggesting that if individuals have strong or weak dispositional self-control, they and their 
partners reap the benefits or suffer the costs, respectively. We then discuss findings suggesting that if partners experience temporarily depleted self-control, they have fewer resources to devote to the relationship, whereas if they experience bolstered self-control over time, they have more resources to devote to the relationship.

\section{Individual Differences in Self-Regulatory Strength}

People vary in the degree to which they can regulate themselves successfully; some people are better able than others to direct their thoughts, feelings, and behavior in a manner that facilitates goal attainment. Moreover, according to the strength model of selfregulation, all acts of self-regulation draw on a single, limited resource called self-regulatory strength (Baumeister, Vohs, \& Tice, 2007; Muraven \& Baumeister, 2000). Just as some individuals have greater physical strength than others do, some individuals have greater selfregulatory strength than others do. These differences are reflected by people's responses on a diverse array of measures, including selfreports, behavioral observation, cognitive tasks, and functional magnetic resonance imaging (fMRI) of the brain. A growing body of research has demonstrated that individual differences in selfregulatory strength, as measured in each of these ways, have important implications for relationship processes and outcomes.

In research using self-report questionnaires to measure individual differences in self-regulatory strength, participants typically indicate their agreement with statements designed to assess general selfregulatory success (e.g., "I am good at resisting temptation," "Pleasure and fun sometimes keep me from getting work done" [reversed]; Tangney, Baumeister, \& Boone, 2004). Participants who rate themselves as high in general self-regulatory success tend to report experiencing more satisfying relationships and behaving more positively and less negatively in their relationships than their counterparts who rate themselves as low in general self-regulatory success. Specifically, individuals who report high levels of self-control experience greater family cohesion and less family conflict, as well as more secure attachment and less anxious and avoidant attachment, than those who report low levels of self-control (Tangney et al., 2004). They also respond to partner offenses more constructively and less destructively, perpetrate fewer acts of intimate partner violence, are less likely to be "on the lookout" for attractive alternative partners, and 
respond to interpersonal anger by engaging in rational discussion instead of "bottling up" their anger or "venting" it through aggressive behavior (Finkel \& Campbell, 2001; Finkel, DeWall, Slotter, Oaten, \& Foshee, 2009; Miller et al., 2010; Tangney et al., 2004).

In research using behavioral observation to measure individual differences in self-regulatory strength, the assessment typically places participants in a situation in which they are tempted to behave in a manner that satisfies a short-term desire but obstructs their attainment of a more important long-term goal. For example, in wellknown research using the delay of gratification paradigm (Mischel, 1974), preschoolers were shown two rewards varying in desirability (e.g., one marshmallow and two marshmallows). The experimenter explained that she had to leave the room and that if the child waited until she returned, he could have the more desirable treat, but if he did not want to wait until she returned, he could have the less desirable treat right away. The number of seconds children waited for the experimenter to return before choosing to have the less desirable treat predicted their parents' ratings of important social outcomes 10 years later. Specifically, children who delayed gratification longer were described as being better able to maintain friendships and get along with peers, more considerate and cooperative, and less likely to tease other children than those who delayed gratification for shorter periods of time (Mischel, Shoda, \& Peake, 1988). Moreover, subsequent research has indicated that the link between children's ability to delay gratification and their later interpersonal functioning may be especially strong for rejection-sensitive children (Ayduk et al., 2000), who are particularly at risk for adverse social outcomes. Although delay of gratification did not predict teachers' reports of less aggressive behavior and greater peer acceptance among socially secure children, it did for socially insecure children. Thus, the ability to delay gratification appeared to buffer rejection-sensitive children from the interpersonal problems that their social anxiety may otherwise have incurred.

In another research program, individuals born in Dunedin, New Zealand, during a 1-year period in the early 1970s were assessed nine times between the ages of 3 and 21 (Caspi, 2000). At 3 years of age, each child completed a 90-min. study session, after which the child's examiner rated the child on 22 behavioral characteristics. Relative to their well-adjusted counterparts, undercontrolled children, who were rated as impulsive, restless, distractible, and emotionally labile, expe- 
rienced inferior interpersonal functioning from ages 5 to 21. From ages 5 to 11 , undercontrolled children were described by their parents and teachers as exhibiting more externalizing problems (e.g., fighting, bullying, lying, disobeying). At age 18, they reported greater enjoyment of causing discomfort to others (i.e., aggression) and greater feelings of being mistreated, deceived, and betrayed by others (i.e., alienation). At age 21, they reported greater conflict and less intimacy and trust in their close relationships. In sum, 3-year-olds who lacked self-regulatory strength grew up to experience more conflicted and less satisfying relationships throughout childhood and into adulthood.

In research using cognitive tasks to measure individual differences in self-regulatory strength, the assessment typically places participants in a situation in which they are required (a) to inhibit a dominant but incorrect response in favor of acting upon a weaker but correct response or (b) to divide and switch their attention to complete two tasks simultaneously. For example, in the Stroop (1935) color-naming task, participants must inhibit their automatic tendency to read the name of a color (e.g., green) and instead report the color font in which the name was presented (e.g., red). In the computation span task (Oberauer, Süß, Schulze, Wilhelm, \& Wittmann, 2000), participants must indicate whether equations are true or false while memorizing the results of the equations so they can report them later. People vary in their ability to complete these cognitive self-regulation tasks, and this variability serves as a measure of self-regulatory strength. Results from research using these cognitive tasks support the behavioral observation findings: Participants who complete these tasks more successfully behave more constructively and less destructively in their relationships than their counterparts who have a more difficult time completing these tasks. Specifically, individuals who do well on cognitive self-regulatory tasks are more polite, are more forgiving of a close other's offenses, and, among those involved in romantic relationships, are rated as less flirtatious when interacting with an attractive confederate of the other sex (Pronk, Karremans, Overbeek, Vermulst, \& Wigboldus, 2010; Pronk, Karremans, \& Wigboldus, 2011; von Hippel \& Gonsalkorale, 2005).

In one line of research, victims of recent interpersonal betrayals who performed well on a cognitive self-regulation task reported steadily increasing levels of forgiveness during a 5-week period, whereas those who performed poorly reported increasing levels of forgiveness during the first 2 weeks followed by a leveling off of 
forgiveness during the last 2 weeks (Pronk, Karremans, Overbeek, et al., 2010). By the end of the study, the levels of forgiveness offered by those with high versus low self-regulatory strength diverged, such that greater self-regulatory strength predicted greater levels of forgiveness. Follow-up studies revealed that the link between self-regulatory strength and forgiveness is especially strong when responding to severe transgressions, presumably because it requires more effort to forgive severe than mild transgressions. Further, individuals with greater self-regulatory strength ruminated less about the offense than those with less self-regulatory strength; this reduced tendency toward rumination appears to be one way in which selfregulatory strength facilitates forgiveness.

Hofmann and colleagues (Hofmann, Friese, \& Strack, 2009) recently proposed that self-regulatory strength determines whether an individual's automatic or controlled precursors of self-control outcomes better predict their behavior. Specifically, they hypothesized that automatic precursors such as implicit attitudes and impulses predict behavior better for individuals with low relative to high self-regulatory strength, whereas controlled precursors such as explicit attitudes and conscious self-restraint goals predict behavior better for individuals with high relative to low self-regulatory strength. In one study testing this model, men viewed erotic pictures and pieces of abstract art for as long as they chose before answering questions about the images (Hofmann, Gschwendner, Friese, Wiers, $\&$ Schmitt, 2008). There was no main effect of participants' selfregulatory strength, as measured by a cognitive self-regulation task, on their viewing time of the erotic pictures relative to their viewing time of the abstract art. However, automatic attitudes toward erotic stimuli predicted relative viewing time among those with low selfregulatory strength, whereas explicit attitudes toward erotic stimuli predicted relative viewing time among those with high self-regulatory strength. Thus, self-regulatory strength appears to facilitate relationship-promoting behavior for those who consciously want to foster their relationship, even if they, perhaps unknowingly, harbor relationship-deteriorating automatic inclinations.

Research using brain imaging techniques has further supported the importance of dispositional self-regulatory strength for interpersonal outcomes. Activation of the lateral prefrontal cortex (LPFC) when exposed to potentially distressing stimuli has been linked to better emotion regulation (Ochsner, Bunge, Gross, \& Gabrieli, 
2002). In one study building on that finding, participants viewed photographs of their romantic partner with neutral and negative facial expressions during an fMRI brain scan (Hooker, Gyurak, Verosky, Miyakawa, \& Ayduk, 2010). They subsequently completed a 3-week daily diary, reporting whether or not a conflict occurred in their romantic relationship and the amount of ruminative thoughts about past relationship conflicts they experienced. Greater activation in the LPFC when viewing one's partner's negative relative to neutral facial expression predicted better self-regulation following relationship conflicts. Specifically, when participants did not report a conflict, LPFC activity did not predict ruminative thoughts the following day, but when participants did report a conflict, greater relative LPFC activity predicted less ruminative thoughts the following day.

In sum, multiple programs of research - including those measuring individual differences in self-regulatory strength using selfreports, behavioral observation, cognitive tasks, and brain-imaging techniques-yield the same conclusion: Greater self-regulatory strength predicts better relationship outcomes. Moreover, research that has investigated whether there can be "too much of a good thing" when it comes to self-regulatory strength has failed to find any evidence that this is the case (Tangney et al., 2004). In addition, there is evidence that the summed total of self-regulatory strength for both partners in a romantic relationship predicts relationship quality and longevity better than the difference in self-regulatory strength between the partners (Vohs, Baumeister, \& Finkenauer, 2011). That is, individuals with low self-regulatory strength tend to fare better in relationships with partners who have high selfregulatory strength than in relationships with partners who have levels of self-regulatory strength similar to their own. Furthermore, individuals with high self-regulatory strength cannot "make up for" a partner who has low self-regulatory strength. When it comes to self-regulatory strength, more of it-in oneself and in one's partner-is better for relationships.

\section{Situational Fluctuations in Self-Regulatory Strength}

According to the strength model of self-regulation, just as physical strength can be depleted by prior exertions, so too can self-regulatory strength be depleted (Baumeister et al., 2007; Muraven \& Baumeister, 
2000). Several studies have shown that depleted self-regulatory resources have deleterious consequences for relationship functioning. For example, depleted individuals tend to respond to partner offenses less constructively than nondepleted individuals do (Finkel \& Campbell, 2001). They also exhibit less effective self-presentation (Vohs, Baumeister, \& Ciarocco, 2005): Compared to their nondepleted counterparts, they tend to talk too much, to disclose too much or too little information about themselves, and to take credit for success but deny responsibility for failure. In one study, members of dating couples either did or did not complete an emotion-suppression task prior to working with their partner to build a physical structure out of blocks. Then they received feedback indicating that their structure was either very creative or not at all creative. Those who had been depleted by suppressing their emotions in a previous task exhibited a self-serving bias: They took credit for creative structures but passed the blame for uncreative ones. Furthermore, when their selfregulatory resources are not depleted, romantically involved individuals show less interest in attractive opposite-sex others than single individuals; this difference disappears when self-regulatory resources are depleted (Ritter, Karremans, \& van Schie, 2010).

Furthermore, depleted individuals retaliate more aggressively in response to provocation by both strangers and close others than their nondepleted counterparts (DeWall, Baumeister, Stillman, \& Gailliot, 2007; Finkel et al., 2009). In one study, members of dating couples either did or did not complete a depleting attentionregulation task prior to experiencing or not experiencing a provocation by their partners (Finkel et al., 2009). Then the experimenter told them they had been randomly assigned to be the director and their partner to be the actor in the next task. As the director, they could determine how many yoga poses their partner had to complete and for how long their partner had to hold each pose. The experimenter informed the participants that the poses tend to be painful but do not cause any long-term physical damage. Participants who had been depleted by regulating their attention in a previous task forced their partner to maintain painful body poses for longer than those who had not regulated their attention, but only when their partner had provoked them.

Thus, depleted levels of self-regulatory strength can lead to maladaptive social behavior. According to the strength model of selfregulation, though, just as physical strength can be built up over time 
with training, so too can self-regulatory strength be built up over time (Baumeister, Gailliot, DeWall, \& Oaten, 2006). To date, one study has shown that bolstered self-regulatory resources have advantageous consequences for relationship functioning (Finkel et al., 2009). Specifically, members of dating couples attended two laboratory sessions, 2 weeks apart, at which they were depleted prior to reporting how likely they would be to respond in a physically aggressive manner to various partner transgressions (e.g., "I find out that my partner has been flirting with someone," "My partner threatens to leave me"). Before leaving the first session, participants were assigned to follow either (a) one of two regimens designed to bolster self-regulatory resources over time (i.e., regulating their physical behavior by using their nondominant hand for mundane tasks or regulating their verbal behavior by, e.g., saying the word yes instead of yeah and avoiding sentences starting with the word $I$ ) or (b) a no-intervention control condition during the 2 weeks between sessions. Participants in both bolstering regimens exhibited significant reductions in their inclinations to perpetrate intimate partner violence in response to the upsetting situations from the first to the second session, whereas participants in the control condition exhibited no change in their inclinations to perpetrate intimate partner violence.

\section{Self-Regulatory Content}

The research we reviewed in the previous section described the effects of differences in self-regulatory strength on relationship outcomes. A second aspect of self-regulation that impacts close relationships is the content of the goals individuals pursue. By content, we mean the objects of goal pursuits - what individuals seek to achieve by altering their thoughts, feelings, and behaviors. In this section, we review how the content of individuals' interpersonal and personal goals affects the quality of their close relationships. We discuss findings suggesting that if individuals try to protect themselves from the pain of rejection, they cannot simultaneously develop close, interdependent relationships and that if they try to guard against threats to their relationships, they may miss opportunities to seek ideal mates. We also discuss findings suggesting that when individuals facilitate their partner's personal goal pursuits, their relationship strengthens; when they obstruct their partner's personal goal pursuits, their relationship deteriorates. 


\section{Interpersonal Goal Content}

Individuals involved in close relationships must balance multiple sets of interpersonal goal contents. These include relationship-promotion and self-protection goals as well as mate-search and mate-guarding goals. The interpersonal goals individuals pursue affect the quality of their relationships. On one hand, individuals involved in close relationships want to promote closeness to their partners; on the other, they want to protect themselves from rejection and hurt (Murray, Holmes, \& Collins, 2006). Pursuing one of these interpersonal goals typically interferes with pursuit of the other. To foster a satisfying relationship, people must be responsive to their partner's needs, rely on their partner for support, and express love and concern for their partner; in short, they must become dependent on their partner. However, doing so puts them at greater risk for rejection and hurt. To guard themselves from such rejection and hurt, people must distance themselves from and become less dependent on their partner, but doing so obstructs the development and maintenance of a satisfying relationship (Murray, Bellavia, Rose, \& Griffin, 2003). It follows that experiencing satisfying, lasting relationships requires that close relationship partners emphasize their relationshippromoting goals over their self-protective goals.

According to the risk regulation model (Murray et al., 2006), individuals can pursue relationship-promotion goals instead of selfprotective goals if they believe their partner holds them in high regard. Confidence in a partner's regard functions as "psychological insurance" that allows individuals to quell their fears of rejection and focus on being good relationship partners (Murray, 2005; Murray \& Holmes, 2008). An extensive program of research has shown that individuals with high and low self-esteem (presumed to perceive their partner as having high vs. low regard for them, respectively) respond differently to threats of rejection. In response to threats of rejection, those with high self-esteem tend to affirm their partner and enhance closeness in their relationship, whereas those with low self-esteem tend to derogate their partner and reduce closeness in their relationship.

In one study, members of dating couples completed paper-andpencil questionnaires with their backs toward each other (Murray, Rose, Bellavia, Holmes, \& Kusche, 2002). Although participants were led to believe they were completing identical questionnaires, in reality, one member of each couple completed a questionnaire asking 
the participant to list important aspects of their partner's character they disliked while the other member of each couple completed a questionnaire asking the participant to list at least 25 items in their dormitory or apartment. Thus, participants completing the former questionnaire were led to believe that their partners were listing many things their partner didn't like about them. This manipulation decreased participants' confidence in their partner's regard, regardless of their level of self-esteem. However, participants with high self-esteem, who have a history of high perceived partner regard, responded to these rejection threats by describing their partner more positively and drawing closer to their partner. In contrast, participants with low self-esteem, who have a history of low perceived partner regard, responded to these rejection threats by describing their partner more negatively and distancing themselves from their partner.

As this line of research illustrates, individuals in close relationships confront conflicting interpersonal goals. They must decide whether to pursue relationship-promotion goals at the expense of self-protection goals, or vice versa. Such decisions are consequential because they affect the well-being of their relationship. Prioritizing relationship-promotion goals tends to yield more satisfying, more committed, and closer relationships than prioritizing self-protection goals (Murray et al., 2006). In addition, and ironically, pursuing self-protection goals tends to bring about the very outcomes those who pursue self-protection goals most wish to avoid. In a daily diary study, those who responded to feelings of vulnerability and rejection in a self-protective manner one day were evaluated more negatively by their partners the next day (Murray et al., 2003). Thus, preemptively protecting oneself from rejection predicts an increased likelihood of subsequent rejection.

Individuals who are involved or want to be involved in romantic relationships face a second set of potentially conflicting interpersonal goals. On one hand, individuals may be motivated to find an appealing romantic partner (or a partner who is more appealing than their current partner); on the other, they may be motivated to prevent a rival from stealing their current partner (Maner, Gailliot, Rouby, \& Miller, 2007). A series of experiments demonstrated that activating a mate-search motivation increases attention to physically attractive members of the other sex (i.e., potential mates) among participants who are generally receptive to casual sexual liaisons, whereas acti- 
vating a mate-guarding motivation increases attention to physically attractive members of the same sex (i.e., potential rivals) among participants who are generally concerned with threats posed by same-sex competitors. Because attentional capacity is limited, paying attention to potential mates may leave one without enough attentional capacity to pay attention to potential rivals, and vice versa. Moreover, among those currently involved in romantic relationships, using one's attentional capacity to attend to either potential alternative mates or potential rivals may limit one's ability to attend to one's current partner. Thus, pursuing either mate-search or mateguarding goals may obstruct one's ability to foster a satisfying relationship.

\section{Personal Goal Content}

According to interdependence theory, relationship partners have extensive opportunities to facilitate or obstruct each other's goal pursuits in their everyday interactions (Kelley, 1979). Several models of relationship functioning have built on this notion and have proposed that relationship partners' influences on each other's personal goal pursuits-including pursuit of temporarily activated goals, fundamental psychological needs, and ideal-self goals-yield corresponding outcomes in relationship well-being. The emotions-inrelationships model posits that emotion is experienced when a relationship partner behaves in an unexpected way (Berscheid, 1983, 1991; Berscheid \& Ammazzalorso, 2001; Fehr \& Harasymchuk, 2005). The partner can unexpectedly facilitate one's goals, resulting in positive emotions toward the partner and relationship, or can unexpectedly thwart one's goals, resulting in negative emotions toward the partner and relationship. Thus, relationships benefit when partners help each other realize their personal goals, especially when they do so to a greater extent than was expected.

Another program of research has relied on a social-cognitive perspective on self-regulation (e.g., Bargh, Gollwitzer, Lee-Chai, Barndollar, \& Trötschel, 2001; Kruglanski et al., 2002) to examine the ways in which partners' facilitative versus obstructive effects on each other's personal goal pursuits influence relationship outcomes (Fitzsimons \& Shah, 2008). In each of a series of experiments, participants first nominated close relationship partners who tend to facilitate their achievement of various personal goals (i.e., instrumen- 
tal others) or tend not to affect their achievement of these goals (i.e., noninstrumental others). Then they completed either a task designed to bring to mind a specific personal goal (e.g., academic achievement, physical fitness) or a control task. Participants in the goal prime condition felt closer to those they had identified as instrumental for the activated goal than those they had identified as noninstrumental, but those in the control condition felt approximately equally close to instrumental and noninstrumental others. Thus, the findings suggest that personal goals can impact people's feelings of closeness to their relationship partners.

In a subsequent study, instead of reporting closeness, participants completed a reaction time task assessing their implicit motivation to approach and avoid close others (Fitzsimons \& Shah, 2008). On trials in which a relevant goal was subliminally primed, participants approached close others they had identified as instrumental for the primed goal faster than close others they had identified as noninstrumental, but on control trials they approached instrumental and noninstrumental others approximately with equal speed. A follow-up study demonstrated that individuals who indicated a stronger preference for achievement-instrumental friends when academic achievement was activated (relative to when it was not) showed better self-regulatory skills, more closely following their study plans for an upcoming midterm and earning higher grades on the midterm than those who did not. Thus, it may be the case that partners who facilitate each other's personal goals enjoy not only closer relationships but also greater success in their personal goal pursuits.

Complementing the work examining partner instrumentality in achieving temporarily activated personal goals, another line of research has demonstrated that partner instrumentality in fulfilling one's fundamental psychological needs also yields relationship benefits. Self-determination theory posits that all humans share three basic psychological needs: (a) autonomy, which is the need to feel agentic; (b) competence, which is the need to feel capable; and (c) relatedness, which is the need to feel connected to others (Deci \& Ryan, 1991; Ryan $\&$ Deci, 2001). Fulfillment of these needs contributes to psychological well-being (Reis, Sheldon, Gable, Roscoe, \& Ryan, 2000), and having a close relationship partner who facilitates the fulfillment of these needs predicts enhanced feelings of security, satisfaction, and commitment in that relationship (La Guardia, Ryan, Couchman, \& Deci, 
2000; Patrick, Knee, Canevello, \& Lonsbary, 2007). Moreover, participants whose relationships were characterized by the highest levels of satisfaction and the lowest levels of conflict reported not only that their partner helped them achieve their basic needs but also that they helped their partner achieve these needs (Patrick et al., 2007).

Research on the Michelangelo phenomenon has shown that partner instrumentality in achieving one's ideal-self goals also yields personal and relational benefits (Drigotas, Rusbult, Wieselquist, \& Whitton, 1999; for a review, see Rusbult, Finkel, \& Kumashiro, 2009). Individuals are most likely to make progress toward achieving their ideal-self goals when their close relationship partners perceive and treat them as if they have already achieved these goals. In one study, participants whose partner affirmed their ideal self by treating them in a manner that is congruent with their ideal self at the beginning of the study reported greater movement toward their ideal self at the second wave of data collection, approximately 1 month later (Drigotas et al., 1999). Further, individuals who make progress toward achieving their ideal-self goals experience relational benefits. In the same study, participants who reported greater movement toward their ideal self at the second wave of data collection experienced greater relationship well-being at the third wave.

\section{Self-Regulatory Strategies}

The research we reviewed in the previous sections described the effects of differences in self-regulatory strength and content on relationship outcomes. A third aspect of self-regulation that affects close relationships is the strategies individuals employ to pursue their goals. By strategies, we mean the broad goal orientations or how people pursue goals, as opposed to the specific goals they are pursuing. In this section, we review how the strategies with which individuals pursue goals, including approach versus avoidance strategies and promotion versus prevention strategies, affect the quality of their close relationships. This research differs from the work on relationship promotion and self-protection reviewed earlier insofar as (a) the previous research focused on relationship promotion and self-protection as specific desired end states (goals) that individuals seek to achieve and (b) the present research on strategies emphasizes general orientations with relevance to the pursuit of a broad range of desired end states. 
We discuss findings suggesting that when partners adopt a selfregulatory strategy focused on attaining positive relationship outcomes, the extent to which they experience positive outcomes in the relationship largely determines their satisfaction, whereas if they adopt a self-regulatory strategy focused on avoiding negative relationship outcomes, the extent to which they experience negative outcomes in the relationship largely determines their satisfaction. We also discuss recent findings suggesting that the extent to which partners frame their relationship goals in terms of promotion versus prevention orientations can affect important relationship outcomes.

\section{Approach and Avoidance Goal Orientations}

According to the approach-avoidance research perspective, goals can be pursued following one of two strategies: (a) approaching positive end states or (b) avoiding negative end states (Carver \& White, 1994; Elliot \& Covington, 2001; Gray, 1990; for an application to relationship outcomes, see Gable, 2006). Applied to the goal of having a successful relationship, individuals who adopt an approach strategy might direct their effort toward end states such as fostering intimacy and developing trust, whereas individuals who adopt an avoidance strategy might direct their effort toward end states such as circumventing conflict and avoiding rejection.

The degree to which individuals adopt approach and avoidance orientations when pursuing goals in their close relationships affects both the determinants of satisfaction and the levels of satisfaction they experience in those relationships. In an experience-sampling study in which participants were randomly signaled several times a day to report their momentary positive and negative feelings about their relationship, individuals who pursue their goals with strong approach tendencies appeared to base their daily relationship satisfaction ratings on the positive feelings (e.g., passion) they experienced that day, whereas those who pursue their goals with weak approach tendencies did not seem to consider their positive feelings when making their satisfaction ratings (Gable \& Poore, 2008). Conversely, individuals who pursue their goals with strong avoidance tendencies appeared to base their daily relationship satisfaction ratings on the negative feelings (e.g., anxiety) they experienced that day, whereas those who pursue their goals with weak avoidance tendencies did not seem to consider their negative feelings when 
making their satisfaction ratings. Thus, individuals may evaluate their relationships based on relational features that correspond to their prevailing self-regulatory strategy.

Whether individuals enact specific relationship behaviors using an approach or avoidance strategy influences the effect these behaviors have on relationship outcomes. For instance, individuals who make sacrifices in their relationship for approach reasons, such as to develop a closer relationship with their partner or to feel good about themselves, subsequently experience better relationship adjustment and are less likely to break up with their partner in the following month (Impett, Gable, \& Peplau, 2005). Conversely, individuals who make sacrifices for avoidance reasons, such as to prevent their partner from seeing them negatively or to avoid feeling guilty, subsequently experience worse relationship adjustment and are more likely to break up with their partner. Similarly, engaging in sexual contact with one's partner for approach reasons predicts better relationship adjustment, whereas engaging in sexual contact with one's partner for avoidance reasons predicts worse relationship adjustment (Impett, Peplau, \& Gable, 2005). Further, pursuing various relationship goals with an approach orientation buffers individuals against declines in sexual desire over time (Impett, Strachman, Finkel, \& Gable, 2008). Thus, the extent to which individuals pursue their interpersonal goals with approach versus avoidance orientations can predict important relationship outcomes, such that approach orientations tend to make those goals - and the overall relationships-more successful.

\section{Promotion and Prevention Goal Orientations}

According to regulatory focus theory, individuals not only approach positive end states (i.e., gains) and avoid negative end states (i.e., losses), but they also approach non-losses and avoid non-gains (Higgins, 1997; Molden, Lee, \& Higgins, 2008). Thus, goals can be pursued following one of two strategies: (a) with a promotion focus, in which individuals strive for gains over non-gains and eagerly pursue opportunities for advancement and growth, or (b) with a prevention focus, in which individuals strive for non-losses over losses and vigilantly pursue opportunities to maintain safety and security. Applied to the goal of having a successful relationship, individuals who adopt a promotion focus might approach an oppor- 
tunity to foster intimacy or avoid missing an opportunity to do so, whereas individuals who adopt a prevention focus might avoid a situation that is likely to cause conflict or approach a situation that is unlikely to do so.

The degree to which individuals adopt promotion and prevention orientations when pursuing goals affects the extent to which they enact certain negative relationship behaviors, the reasons why they enact certain positive relationship behaviors, and the circumstances under which other positive relationship behaviors most benefit their relationships. One line of research has examined the association of individual differences in regulatory focus with evaluations of romantic alternatives (Finkel, Molden, Johnson, \& Eastwick, 2009). Individuals with a strong promotion focus tend to attend to, positively evaluate, and actively pursue potential alternative partners to a greater degree than individuals with a strong prevention focus. In addition, the negative association between commitment to one's current partner and evaluations of potential alternatives to that partner is weaker for promotion-focused than for prevention-focused individuals.

A second line of research has examined the predictors of forgiveness for promotion-focused and prevention-focused individuals (Molden \& Finkel, 2010). When deciding whether to forgive a partner, promotion-focused individuals are likely to consider the benefits that can be attained by repairing the relationship. Feelings of trust in a relationship partner may reflect one's belief that something may be gained if the relationship is repaired. When deciding whether to forgive a partner, prevention-focused individuals, however, are likely to consider the potential costs of further relationship deterioration. Feelings of commitment toward a relationship partner may reflect one's belief that something may be lost if the relationship deteriorates. If this is the case, trust should motivate forgiveness especially for individuals with a strong promotion focus, and commitment should motivate forgiveness especially for individuals with a strong prevention focus. Supporting this logic, experimental and longitudinal studies showed that trust predicted forgiveness of a relationship partner to a greater extent for individuals adopting a promotion rather than a prevention focus, whereas commitment predicted forgiveness to a greater extent for individuals adopting a prevention rather than a promotion focus.

A third line of research has examined the circumstances under which perceived partner support for one's personal goals yields the 
greatest benefits for one's relationship (Molden, Lucas, Finkel, Kumashiro, \& Rusbult, 2009). Unmarried romantic partners may evaluate their relationships primarily in terms of how it is advancing and whether or not intimacy and closeness are growing and developing. That is, dating partners may primarily adopt a promotion orientation in their relationship. Married romantic partners, however, may evaluate their relationships not only in terms of these advancement goals but also in terms of how it is "holding up" and whether it provides security and maintains relational investments. That is, married partners may simultaneously adopt both promotion and prevention orientations in their relationship. If this is the case, perceived partner support for one's promotion-focused goals should predict relationship quality among both dating and married partners, whereas perceived partner support for one's prevention-focused goals should predict relationship quality only among married partners. Supporting this logic, a longitudinal study showed that perceived support for one's personal goals predicts the strongest relationship functioning-operationalized in terms of trust, intimacy, and satisfaction-when the support matched the general motivational orientation of the relationship itself, with promotion support benefiting both dating and married partners and prevention support benefiting only married partners.

An additional line of research has examined how complementarity in relationship partners' regulatory focus orientations affects relationship well-being (Bohns et al., 2011). Much research indicates that similarity generally predicts attraction and relationship quality more strongly than complementarity does (e.g., Byrne, 1971; Gonzaga, Campos, \& Bradbury, 2007; for an exception in the dominancesubmissiveness domain, see Dryer \& Horowitz, 1997; Tiedens \& Fragale, 2003). Nevertheless, for relationship partners who are working together to pursue mutual goals, complementarity in regulatory focus may be advantageous because it allows couples to coordinate their goal pursuit so that each partner takes primary responsibility for aspects of the shared goals that fit his or her preferred strategy. That is, the more promotion-focused partner could pursue tasks requiring eager strategies, and the more preventionfocused partner could pursue tasks requiring vigilant strategies. Supporting this logic, a series of studies showed that complementarity in regulatory focus orientations predicts relationship satisfaction, commitment, and adjustment, but only for highly interdependent couples 
who shared common goals. Thus, as with the work on approach and avoidance orientations, research on regulatory focus has suggested that interpersonal outcomes will vary depending not only on what goals people pursue in relationships but also on how people pursue those goals.

Self-Regulatory Strategies for the Pursuit of Specific Self-Regulatory Contents

In addition to research on the relational consequences of approach and avoidance goal orientations and of promotion and prevention goal orientations, several other lines of research have examined the relational consequences of self-regulatory strategies for the pursuit of specific self-regulatory contents. Although these lines of research could have fit in the second section of this review article because of their emphasis on specific self-regulatory content, we review them in this third section because of their emphasis on the self-regulatory strategies individuals use to pursue their goals. We review how the strategies individuals use to regulate their attention, emotions, and self-image affect the quality of their close relationships. Specifically, we discuss findings suggesting that mindfulness strategies for regulating one's attention, reappraisal strategies (but not suppression strategies) for regulating one's emotion, and guilt-based strategies (but not shame-based strategies) for regulating one's self-image lead to positive relationship outcomes.

Mindfulness strategies for regulating attention. Mindfulness, which is the practice of focusing one's attention on what is taking place in the present, has been linked to psychological benefits and has been incorporated into treatments for various psychological problems (e.g., Kabat-Zinn et al., 1992; Segal, Williams, \& Teasdale, 2002). Recent work has examined whether mindfulness strategies for regulating one's attention to focus on the present are also linked to relational benefits. In one study, greater dispositional mindfulness predicted greater relationship adjustment and satisfaction among dating couples (Barnes, Brown, Krusemark, Campbell, \& Rogge, 2007). It also predicted less verbal aggression and negative communication during conflict and less anger and anxiety following conflict (Barnes et al., 2007). Interventions aimed to increase general mindfulness led to greater perspective taking and empathic concern as 
well as stronger feelings of closeness, relatedness, and acceptance (Block-Lerner, Adair, Plumb, Rhatigan, \& Orsillo, 2007; Carson, Carson, Gil, \& Baucom, 2004).

Emerging evidence suggests that interventions focused on promoting mindfulness in specific relationship contexts - as opposed to general mindfulness in life - are also successful. For example, a case study of two married couples indicated that acceptance and commitment therapy, which teaches mindfulness techniques aimed to increase clients' attention to their responses to relationship circumstances in the present moment, may increase marital adjustment and satisfaction while decreasing interpersonal and psychological distress (Peterson, Eifert, Feingold, \& Davidson, 2009). In addition, a study of 65 mothers and their 10- to 14-year-old children indicated that mothers who participated in a mindful parenting intervention experienced more positive and less negative affect and behavior from their children than mothers who participated in a parenting intervention that did not include mindfulness training (Coatsworth, Duncan, Greenberg, \& Nix, 2010). Furthermore, this difference was mediated by increases in the mothers' presentcentered attention and awareness of her own and her child's moods, behaviors, and reactions to relationship interactions. To summarize, both general and relationship-specific mindfulness strategies for regulating one's attention to the present predict positive relationship outcomes.

Reappraisal and suppression strategies for regulating emotion. Reappraisal and suppression are two commonly used strategies for down-regulating emotion. Reappraisal involves changing the way one construes a situation in order to decrease its emotional impact, whereas suppression involves inhibiting the outward signs of one's inner feelings (Gross, 1998). Reappraisal and suppression have been linked, respectively, to a variety of positive and negative outcomes, both within and beyond the interpersonal relationships domain (for a review, see Gross, 2002). In one study, participants recorded their daily levels of social anxiety, use of suppression strategies, and positive activities in daily diaries over a course of 3 weeks (Kashdan $\&$ Steger, 2006). Participants high in dispositional social anxiety reported the lowest number of positive events (e.g., social, achievement, and health activities) on days they both felt particularly socially anxious and suppressed their emotions. In contrast, they 
reported the highest number of positive events on days they both felt less socially anxious and did not suppress their emotions.

Other work has shown that the costs of suppression, as well as the benefits of reappraisal, are not limited to the socially anxious. In one experiment, pairs of women discussed an upsetting topic; one of the women was instructed to suppress, reappraise, or act naturally during the discussion (Butler et al., 2003). Both suppressors and their partners exhibited greater increases in blood pressure than other participants, presumably because suppression impedes social support that otherwise would have decreased participants' physiological reactivity to the stressful discussion. Partners of suppressors also reported experiencing less rapport than partners of reappraisers. A large-scale correlational study extended these findings: Use of reappraisal strategies was associated with more positive relationships with others, higher peer-rated relationship closeness, and greater peer-rated likability (Gross \& John, 2003). In contrast, use of suppression strategies was associated with fewer positive relationships with others, higher attachment avoidance, less emotional and instrumental social support, and lower peer-rated relationship closeness. To summarize, reappraisal strategies for regulating one's emotions predict positive relationship outcomes, whereas suppression strategies for regulating one's emotions predict negative relationship outcomes.

Shame-based and guilt-based strategies for regulating self-image. Self-conscious emotions, such as shame and guilt, are induced by explicit or implicit self-evaluation (Tangney, Stuewig, \& Mashek, 2007). Both shame and guilt are negatively valenced and, as such, can provide immediate punishment for one's real or imagined behavior. Because they do so, shame and guilt have been presumed to inhibit socially unacceptable behavior and control the expression of hostility and aggression (Damon, 1988). Despite their commonalities, there is an important difference between shame and guilt. Specifically, shame involves a negative evaluation of oneself (i.e., "I am bad"), whereas guilt involves a negative evaluation of one's behavior (i.e., "I did something bad"; Lewis, 1971). A body of empirical work shows that shame-based and guilt-based strategies for regulating one's self-image are associated with very different constellations of relationship outcomes (for a review, see Tangney et al., 2007). 
For example, individuals who are prone toward experiencing shame tend to report greater personal distress but less empathic responsiveness than those who are prone toward experiencing guilt (Tangney, 1991). With this difference in mind, it is not surprising that shame is associated with attempts to deny or hide from the shameinducing self-evaluation, whereas guilt is associated with attempts to apologize and make amends for the guilt-inducing behavior (Tangney, Miller, Flicker, \& Barlow, 1996). Furthermore, shameproneness is related to a number of destructive responses to anger, such as indirect expressions of hostility, resentment, and externalization of blame (Tangney, Wagner, Fletcher, \& Gramzow, 1992; Tangney, Wagner, Hill-Barlow, Marschall, \& Gramzow, 1996). Conversely, guilt-proneness is related to constructive responses to anger, such as corrective action and nonhostile discussion with the target of the anger. The divergent relationship outcomes experienced by those who tend to feel shame versus guilt may be partly attributable to their ability to generate and implement solutions to interpersonal problems. Shame-proneness is negatively correlated with the quality of self-generated solutions to common interpersonal problems and with self-efficacy for implementing these solutions; guilt-proneness is positively correlated with these problem-solving activities (Covert, Tangney, Maddux, \& Heleno, 2003). To summarize, shame-based strategies for regulating one's self-image predict negative relationship outcomes, whereas guilt-based strategies for regulating one's self-image predict positive relationship outcomes.

\section{Conclusions}

In this article, we reviewed research describing the effects of selfregulatory strength, content, and strategies on close relationships, focusing primarily on work in social and personality psychology. This area of research has grown rapidly in the past decade and shows no signs of slowing down in the coming decade. Future research might help fill in the gaps made apparent in this review. Specifically, more unanswered questions remain about the relational consequences of self-regulatory content and strategies than about the relational consequences of self-regulatory strength. As one example, although the body of work by Murray and colleagues (e.g., Murray et al., 2003, 2006) indicates that distinguishing between relationshippromotion and self-protection goals is one useful way to categorize 
the content of interpersonal goals, future research might expand on the work examining mate-search and mate-guarding goals (Maner et al., 2007) or delineate other useful ways to categorize the content of interpersonal goals. As another example, although recent work by Bohns and colleagues (2011) indicates that complementary selfregulatory strategies predict positive outcomes for interdependent couples who share common goals, future research might examine whether it is better for couples who share common goals to "join forces" by pursuing the same shared goal at a given point in time or to "divide and conquer" by pursuing different shared goals.

Furthermore, although this article has reviewed the expanding body of work examining the effects of self-regulation on relationships, it has not included the expanding body of work examining the effects of partner regulation - when one partner attempts to regulate the other's relationship behavior - on relationships (Overall, Fletcher, \& Simpson, 2006; Overall, Fletcher, Simpson, \& Sibley, 2009). Future research could compare and contrast the effects of self-regulation and partner regulation on relationships.

We hope that this review highlights not only promising avenues for future research, but also the great strides that have already been made. A decade ago, the bodies of work on self-regulation and on close relationships were largely distinct. Since then, scholars have come to understand the relational effects of having strong versus weak self-regulatory strength, of prioritizing self-interested goals versus relationship-interested goals, and of pursuing goals with various strategies. Just as recent research has fruitfully integrated the fields of self-regulation and close relationships, we hope that future research will fruitfully integrate programs of research examining the effects of self-regulatory strength, content, and strategies on close relationships.

\section{REFERENCES}

Ayduk, O., Mendoza-Denton, R., Mischel, W., Downey, G., Peake, P. K., \& Rodriguez, M. (2000). Regulating the interpersonal self: Strategic selfregulation for coping with rejection sensitivity. Journal of Personality and Social Psychology, 79, 776-792.

Bandura, A. (1982). Self-efficacy mechanism in human agency. American Psychologist, 37, 122-147.

Bargh, J. A., Gollwitzer, P. M., Lee-Chai, A., Barndollar, K., \& Trötschel, R. (2001). The automated will: Nonconscious activation and pursuit of behavioral goals. Journal of Personality and Social Psychology, 81, 1014-1027. 
Barnes, S., Brown, K. W., Krusemark, E., Campbell, W. K., \& Rogge, R. D. (2007). The role of mindfulness in romantic relationship satisfaction and responses to relationship stress. Journal of Marital and Family Therapy, 33, 482-500.

Baumeister, R. F. (2005). The cultural animal: Human nature, meaning, and social life. New York: Oxford University Press.

Baumeister, R. F., Gailliot, M., DeWall, C. N., \& Oaten, M. (2006). Selfregulation and personality: How interventions increase regulatory success, and how depletion moderates the effects of trait on behavior. Journal of Personality, 74, 1773-1802.

Baumeister, R. F., Heatherton, T. F., \& Tice, D. M. (1994). Losing control: How and why people fail at self-regulation. New York: Academic Press.

Baumeister, R. F., Schmeichel, B. J., \& Vohs, K. D. (2007). Self-regulation and the executive function: The self as controlling agent. In A. W. Kruglanski \& E. T. Higgins (Eds.), Social psychology: Handbook of basic principles (2nd ed., pp. 516-539. New York: Guilford Press.

Baumeister, R. F., Vohs, K. D., \& Tice, D. M. (2007). The strength model of self-control. Current Directions in Psychological Science, 16, 351-355.

Berscheid, E. (1983). Emotion. In H. Kelley, E. Berscheid, A. Christensen, J. Harvey, T. Huston, G. Levinger, et al. (Eds.), Close relationships (pp. 110-168). New York: Freeman.

Berscheid, E. (1991). The emotion-in-relationships model: Reflections and update. In W. Kessen, A. Ortony, \& F. I. M. Craik (Eds.), Memories, thoughts, and emotions: Essays in honor of George Mandler (pp. 323-335). Hillsdale, NJ: Erlbaum.

Berscheid, E., \& Ammazzalorso, H. (2001). Emotional experience in close relationships. In M. Hewstone \& M. Brewer (Eds.), Blackwell handbook of social psychology: Interpersonal Processes (Vol. 2, pp. 308-330). Oxford, UK: Blackwell.

Block-Lerner, J., Adair, C., Plumb, J., Rhatigan, D., \& Orsillo, S. (2007). The case for mindfulness-based approaches in the cultivation of empathy: Does nonjudgemental, present-moment awareness increase capacity for perspectivetaking and empathic concern? Journal of Marital and Family Therapy, 33, 501-516.

Bohns, V. K., Lucas G. M., Molden D. C., Finkel E. J., Coolsen, M. K., Kumashiro M., et al. (2011). When opposites fit: Increased relationship wellbeing from partner complementarity in regulatory focus. Unpublished manuscript, University of Toronto.

Butler, E. A., Egloff, B., Wilhelm, F. H., Smith, N. C., Erickson, E. A., \& Gross, J. J. (2003). The social consequences of expressive suppression. Emotion, 3, $48-67$.

Byrne, D. (1971). The attraction paradigm. New York: Academic Press.

Carson, J. W., Carson, K. M., Gil, K. M., \& Baucom, D. H. (2004). Mindfulnessbased relationship enhancement. Behavior Therapy, 35, 471-494.

Carver, C. S., \& White, T. L. (1994). Behavioral inhibition, behavioral activation, and affective responses to impending reward and punishment: The BIS/BAS scales. Journal of Personality and Social Psychology, 67, 319-333. 
Caspi, A. (2000). The child is the father of the man: Personality continuities from childhood to adulthood. Journal of Personality and Social Psychology, 78, $158-175$.

Coatsworth, J. D., Duncan, L. G., Greenberg, M. T., \& Nix, R. L. (2010). Changing parents' mindfulness, child management skills and relationship quality with their youth: Results from a randomized pilot intervention trial. Journal of Child and Family Studies, 19, 203-217.

Covert, M. V., Tangney, J. P., Maddux, J. E., \& Heleno, N. M. (2003). Shameproneness, guilt-proneness, and interpersonal problem solving: A social cognitive analysis. Journal of Social and Clinical Psychology, 22, 1-12.

Damon, W. (1988). The moral child: Nurturing children's natural moral growth. New York: Free Press.

Deci, E. L., \& Ryan, R. M. (1991). A motivational approach to the self: Integration in personality. In R. Dienstbier (Ed.), Nebraska Symposium on Motivation: Perspectives on motivation (Vol. 38, pp. 237-288). Lincoln: University of Nebraska Press.

DeWall, C. N., Baumeister, R. F., Stillman, T. F., \& Gailliot, M. T. (2007). Violence restrained: Effects of self-regulation and its depletion on aggression. Journal of Experimental Social Psychology, 43, 62-76.

Drigotas, S. M., Rusbult, C. E., Wieselquist, J., \& Whitton, S. (1999). Close partner as sculptor of the ideal self: Behavioral affirmation and the Michelangelo phenomenon. Journal of Personality and Social Psychology, 77, 293-323.

Dryer, D. C., \& Horowitz, L. M. (1997). When do opposites attract? Interpersonal complementarity versus similarity. Journal of Personality and Social Psychology, 72, 592-603.

Elliot, A. J., \& Covington, M. V. (2001). Approach and avoidance motivation. Educational Psychology Review, 13, 73-92.

Emmons, R. A. (1986). Personal strivings: An approach to personality and subjective well-being. Journal of Personality and Social Psychology, 51, 1058-1068.

Fehr, B., \& Harasymchuk, C. (2005). The experience of emotion in close relationships: Toward an integration of the emotion-in-relationships and interpersonal script models. Personal Relationships, 12, 181-196.

Finkel, E. J., \& Campbell, W. K. (2001). Self-control and accommodation in close relationships: An interdependence analysis. Journal of Personality and Social Psychology, 81, 263-277.

Finkel, E. J., DeWall, C. N., Slotter, E. B., Oaten, M., \& Foshee, V. A. (2009). Self-regulatory failure and intimate partner violence perpetration. Journal of Personality and Social Psychology, 97, 483-499.

Finkel, E. J., Molden, D. C., Johnson, S. E., \& Eastwick, P. W. (2009). Regulatory focus and romantic alternatives. In J. P. Forgas, R. F. Baumeister, \& D. M. Tice (Eds.), Self-regulation: Cognitive, affective, and motivational processes (pp. 319-335). New York: Psychology Press.

Fitzsimons, G. M., \& Shah, J. Y. (2008). How goal instrumentality shapes relationship evaluations. Journal of Personality and Social Psychology, 95, 319337.

Gable, S. L. (2006). Approach and avoidance social motives and goals. Journal of Personality, 71, 175-222. 
Gable, S. L., \& Poore, J. (2008). Which thoughts count? Algorithms for evaluating satisfaction in relationships. Psychological Science, 19, 1030-1036.

Gonzaga, G. C., Campos, B., \& Bradbury, T. (2007). Similarity, convergence, and relationship satisfaction in dating and married couples. Journal of Personality and Social Psychology, 93, 34-48.

Gray, J. A. (1990). Brain systems that mediate both emotion and cognition. Cognition and Emotion, 4, 269-288.

Gross, J. J. (1998). The emerging field of emotion regulation: An integrative review. Review of General Psychology, 2, 271-299.

Gross, J. J. (2002). Emotion regulation: Affective, cognitive, and social consequences. Psychophysiology, 39, 281-291.

Gross, J. J., \& John, O. P. (2003). Individual differences in two emotion regulation processes: Implications for affect, relationships, and well-being. Journal of Personality and Social Psychology, 85, 348-362.

Heatherton, T. F., \& Vohs, K. D. (1998). Why is it so difficult to inhibit behavior? Psychological Inquiry, 9, 212-216.

Higgins, E. T. (1997). Beyond pleasure and pain. American Psychologist, 52, $1280-1300$.

Hofmann, W., Friese, M., \& Strack, F. (2009). Impulse and self-control from a dual-systems perspective. Perspectives on Psychological Science, 4, 162176.

Hofmann, W., Gschwendner, T., Friese, M., Wiers, R. W., \& Schmitt, M. (2008). Working memory capacity and self-regulatory behavior: Toward an individual differences perspective on behavior determination by automatic versus controlled processes. Journal of Personality and Social Psychology, 95, 962977.

Hooker, C. I., Gyurak, A., Verosky, S. C., Miyakawa, A., \& Ayduk, O. (2011). Neural activity to a partner's facial expression predicts self-regulation after conflict. Biological Psychiatry, 67, 406-413.

Impett, E., Gable, S. L., \& Peplau, L. A. (2005). Giving up and giving in: The costs and benefits of daily sacrifice in intimate relationships. Journal of Personality and Social Psychology, 89, 327-344.

Impett, E. A., Peplau, L. A., \& Gable, S. L. (2005). Approach and avoidance sexual motivation: Implications for personal and interpersonal well-being. Personal Relationships, 12, 465-482.

Impett, E. A., Strachman, A., Finkel, E. J., \& Gable, S. L. (2008). Maintaining sexual desire in intimate relationships: The importance of approach goals. Journal of Personality and Social Psychology, 94, 808-823.

Kabat-Zinn, J., Massion, A. O., Kristeller, J., Peterson, L. G., Fletcher, K., Pbert, L., et al. (1992). Effectiveness of a meditation-based stress reduction program in the treatment of anxiety disorders. American Journal of Psychiatry, 149, 936-943.

Kashdan, T. B., \& Steger, M. F. (2006). Expanding the topography of social anxiety: An experience-sampling assessment of positive emotions, positive events, and emotion suppression. Psychological Science, 17, 120-128.

Kelley, H. H. (1979). Personal relationships: Their structure and processes. Hillsdale, NJ: Erlbaum. 
Kruglanski, A. W., Shah, J. Y., Fishbach, A., Friedman, R., Chun, W. Y., \& Sleeth-Keppler, D. (2002). A theory of goal systems. Advances in Experimental Social Psychology, 34, 311-378.

La Guardia, J. G., Ryan, R. M., Couchman, C. E., \& Deci, E. L. (2000). Withinperson variation in security of attachment: A self-determination theory perspective on attachment, need fulfillment, and well-being. Journal of Personality and Social Psychology, 79, 367-384.

Lewis, H. B. (1971). Shame and guilt in neurosis. New York: International Universities Press.

Locke, E. A., \& Latham, G. P. (2002). Building a practically useful theory of goal setting and task motivation: A 35-year odyssey. American Psychologist, 57, 705-717.

Maner, J. K., Gailliot, M. T., Rouby, D. A., \& Miller, S. L. (2007). Can't take my eyes off you: Attentional adhesion to mates and rivals. Journal of Personality and Social Psychology, 93, 389-401.

Miller, R. W., Paul, L., Quitugua, K., Husband, K., Isgitt, J., Kennedy, E., et al. (2010, January). Attention to relationship alternatives has (at least) three facets. Poster session presented at the annual meeting of the Society for Personality and Social Psychologists, Las Vegas, NV.

Mischel, W. (1974). Processes in delay of gratification. In L. Berkowitz (Ed.), Advances in experimental social psychology (Vol. 7, pp. 249-292). New York: Academic Press.

Mischel, W., Shoda, Y., \& Peake, P. K. (1988). The nature of adolescent competencies predicted by preschool delay of gratification. Journal of Personality and Social Psychology, 54, 687-696.

Mischel, W., Shoda, Y., \& Rodriguez, M. I. (1989). Delay of gratification in children. Science, 244, 933-938.

Molden, D. M., \& Finkel, E. J. (2010). Motivations for promotion and prevention and the role of trust and commitment in interpersonal forgiveness. Journal of Experimental Social Psychology, 46, 255-268.

Molden, D. C., Lee, A. Y., \& Higgins, E. T. (2008). Motivations for promotion and prevention. In J. Shah \& W. Gardner (Eds.), Handbook of motivation science (pp. 169-187). New York: Guilford Press.

Molden, D. C., Lucas, G. M., Finkel, E. J., Kumashiro, M., \& Rusbult, C. E. (2009). Perceived support for promotion-focused and prevention-focused goals: Associations with well-being in unmarried and married couples. Psychological Science, 20, 787-793.

Muraven, M., \& Baumeister, R. F. (2000). Self-regulation and depletion of limited resources: Does self-control resemble a muscle? Psychological Bulletin, 126, $247-259$.

Murray, S. L. (2005). Regulating the risks of closeness: A relationship-specific sense of felt security. Current Directions in Psychological Science, 14, 74 78.

Murray, S. L., Bellavia, G., Rose, P., \& Griffin, D. (2003). Once hurt, twice hurtful: How perceived regard regulates daily marital interaction. Journal of Personality and Social Psychology, 84, 126-147. 
Murray, S. L., \& Holmes, J. G. (2008). The commitment-insurance system: Selfesteem and the regulation of connection in close relationships. Advances in Experimental Social Psychology, 40, 1-60.

Murray, S. L., Holmes, J. G., \& Collins, N. L. (2006). Optimizing assurance: The risk regulation system in relationships. Psychological Bulletin, 132, 641666.

Murray, S. L., Rose, P., Bellavia, G., Holmes, J. G., \& Kusche, A. (2002). When rejection stings: How self-esteem constrains relationship-enhancement processes. Journal of Personality and Social Psychology, 83, 556-573.

Oberauer, K., Süß, H.-M., Schulze, R., Wilhelm, O., \& Wittmann, W. W. (2000). Working memory capacity: Facets of a cognitive ability construct. Personality and Individual Differences, 29, 1017-1045.

Ochsner, K. N., Bunge, S. A., Gross, J. J., \& Gabrieli, J. D. E. (2002). Rethinking feelings: An fMRI study of the cognitive regulation of emotion. Journal of Cognitive Neuroscience, 14, 1215-1229.

Overall, N. C., Fletcher, G. J. O., \& Simpson, J. A. (2006). Regulation processes in intimate relationships: The role of ideal standards. Journal of Personality and Social Psychology, 91, 662-685.

Overall, N. C., Fletcher, G. J. O., Simpson, J. A., \& Sibley, C. G. (2009). Regulating partners in intimate relationships: The costs and benefits of different communication strategies. Journal of Personality and Social Psychology, 96, 620-639.

Patrick, H., Knee, C. R., Canevello, A., \& Lonsbary, C. (2007). The role of need fulfillment in relationship functioning and well-being: A self-determination theory perspective. Journal of Personality and Social Psychology, 92, 434 456.

Peterson, B. D., Eifert, G. H., Feingold, T., \& Davidson, S. (2009). Using acceptance and commitment therapy to treat distressed couples: A case study with two couples. Cognitive and Behavioral Practice, 16, 430-442.

Pronk, T. M., Karremans, J. C., Overbeek, G., Vermulst, A. A., \& Wigboldus, D. H. J. (2010). What it takes to forgive: When and why executive functioning facilitates forgiveness. Journal of Personality and Social Psychology, 98, 119131.

Pronk, T. M., Karremans, J. C., \& Wigboldus, D. H. J. (2011). How can you resist? Executive control helps romantically involved individuals to stay faithful. Journal of Personality and Social Psychology, 100, 827-837.

Rawn, C. D., \& Vohs, K. D. (2006). The importance of self-regulation for interpersonal functioning. In K. D. Vohs \& E. J. Finkel (Eds.), Self and relationships: Connecting intrapersonal and interpersonal processes. New York: Guilford Press.

Reis, H. T., Sheldon, K. M., Gable, S. L., Roscoe, J., \& Ryan, R. M. (2000). Daily well-being: The role of autonomy, competence, and relatedness. Personality and Social Psychology Bulletin, 26, 419-435.

Ritter, S. M., Karremans, J. C., \& van Schie, H. T. (2010). The role of selfregulation in derogating attractive alternatives. Journal of Experimental Social Psychology, 46, 631-637.

Rusbult, C. E., Finkel, E. J., \& Kumashiro, M. (2009). The Michelangelo phenomenon. Current Directions in Psychological Science, 18, 305-309. 
Ryan, R. M., \& Deci, E. L. (2001). On happiness and human potentials: A review of research on hedonic and eudaimonic well-being. Annual Review of Psychology, 52, 141-166.

Segal, Z. V., Williams, J. M. G., \& Teasdale, J. D. (2002). Mindfulness-based cognitive therapy for depression. New York: Guilford Press.

Stroop, J. R. (1935). Studies of interference in serial verbal reactions. Journal of Experimental Psychology, 18, 643-662.

Tangney, J. P. (1991). Moral affect: The good, the bad, and the ugly. Journal of Personality and Social Psychology, 61, 598-607.

Tangney, J. P., Baumeister, R. F., \& Boone, A. L. (2004). High self-control predicts good adjustment, less pathology, better grades, and interpersonal success. Journal of Personality, 72, 271-322.

Tangney, J. P., Miller, R. S., Flicker, L., \& Barlow, D. H. (1996). Are shame, guilt, and embarrassment distinct emotions? Journal of Personality and Social Psychology, 70, 1256-1269.

Tangney, J. P., Stuewig, J., \& Mashek, D. J. (2007). Moral emotions and moral behavior. Annual Review of Psychology, 58, 354-372.

Tangney, J. P., Wagner, P., Fletcher, C., \& Gramzow, R. (1992). Shame into anger? The relation of shame and guilt to anger and self-reported aggression. Journal of Personality and Social Psychology, 62, 669-675.

Tangney, J. P., Wagner, P. E., Hill-Barlow, D., Marschall, D. E., \& Gramzow, R. (1996). Relation of shame and guilt to constructive versus destructive responses to anger across the lifespan. Journal of Personality and Social Psychology, 70, 797-809.

Tiedens, L., \& Fragale, A. (2003). Power moves: Complementarity in dominant and submissive nonverbal behavior. Journal of Personality and Social Psychology, 84, 558-568.

Vohs, K. D., Baumeister, R. F., \& Ciarocco, N. (2005). Self-regulation and selfpresentation: Regulatory resource depletion impairs impression management and effortful self-presentation depletes regulatory resources. Journal of Personality and Social Psychology, 88, 632-657.

Vohs, K. D., Finkenauer, C., \& Baumesiter, R. F. (2011). The sum of friends' and lovers' self-control scores predicts relationship quality. Social Psychological and Personality Science, 2, 138-145.

von Hippel, W., \& Gonsalkorale, K. (2005). “That is bloody revolting!” Inhibitory control of thoughts better left unsaid. Psychological Science, 16, 497-500. 